\title{
Comparison of the Effects of Bupivacaine, Lidocaine, and Tramadol Infiltration on Wound Healing in Rats
}

\author{
Volkan Hancı ${ }^{1}$, Sedat Hakimoğlu ${ }^{2}$, Haktan Özaçmak ${ }^{3}$, Sibel Bektaş ${ }^{4}$, Hale Sayan Özaçmak ${ }^{5}$, \\ Şükrü Oğuz Özdamar ${ }^{6}$, Serhan Yurtlu ${ }^{7}$, Işıl Özkoçak Turan ${ }^{8}$
}

\begin{abstract}
Summary: Hancı V, Hakimoğlu S, Özaçmak H, Bektaş S, Özaçmak HS, Özdamar ŞO, Yurtlu S, Turan IÖ - Comparison of the Effects of Bupivacaine, Lidocaine, and Tramadol Infiltration on Wound Healing in Rats.

Background and objectives: The aim of this study was to investigate the effects of saline solution, bupivacaine, lidocaine and tramadol infiltration on wound healing in rats.

Method: Thirty-two male Wistar Albino rats were randomly separated into four groups, receiving $3 \mathrm{~mL}$ saline solution in control group (Group C, $\mathrm{n}=8$ ), $3 \mathrm{~mL}$ of $2 \%$ lidocaine in lidocaine group (Group $\mathrm{L}, \mathrm{n}=8$ ), $3 \mathrm{~mL}$ of $0.5 \%$ bupivacaine in bupivacaine group $(\mathrm{Group} B, \mathrm{n}=8$ ), and $3 \mathrm{~mL}$ of $5 \%$ tramadol in tramadol group (Group T, $n=8$ ). Breaking-strength measurements, collagen bundle counting, and histopathologic evaluation were evaluated in the tissue samples taken from the rats.

Results: Comparing the control group with the groups where bupivacaine and lidocaine were used for wound infiltration, collagen production was lower, breaking-strength measurements showed reduced resistance while significantly high edema, vascularity, inflammation scores were found $(p<0.0125)$. Between the control and the tramadol group there were no significant differences in collagen production, breaking-strength measurements, and edema, vascularity, inflammation scores ( $p>0.0125)$.

Conclusion: In our study, we found bupivacaine and lidocaine reduced the collagen production, wound breaking strength, and caused significantly high scores for edema, vascularity, and inflammation when compared to the control group. There was no significant difference between the control and the tramadol group. Results of this experimental preliminary study on rats support the idea that tramadol can be used for wound infiltration anesthesia without adverse effect on the surgical healing process. These results need to be verified in humans.
\end{abstract}

Keywords: Anesthesia, Local; Tramadol; Bupivacaine; Lidocaine; Wound Healing.

\section{INTRODUCTION}

Infiltrating the wound with local anesthetics is increasingly used as a post-operative analgesia method due to its ease of application, simplicity and few side effects ${ }^{1-4}$. Surgical wound

Received from Dokuz Eylül Universitesi Araștırma Uygulama Hastanesi Ameliyathaneleri, Inciraltı, Izmir, Turkey.

1. MD; Associate Professor Doctor; Dokuz Eylül University, School of Medicine, Department of Anesthesiology and Reanimation (Formerly Bulent Ecevit University, School of Medicine, Department of Anesthesiology and Reanimation)

2. MD; Assistant Professor Doctor; Mustafa Kemal University, School of Medicine,

Department of Anesthesiology and Reanimation (Formerly Bulent Ecevit University, School

of Medicine, Department of Anesthesiology and Reanimation)

3. MD; Associate Professor Doctor; Bulent Ecevit University, School of Medicine,

Department of Physiology

4. MD; Associate Professor Doctor; Bulent Ecevit University, School of Medicine,

Department of Pathology

5. MD; Professor Doctor; Bulent Ecevit University, School of Medicine, Department of

Physiology

6. MD; Professor Doctor; Bulent Ecevit University, School of Medicine, Department of Pathology

7. MD, Assistant Professor Doctor; Dokuz Eylül University, School of Medicine, Department of Anesthesiology and Reanimation (Formerly Bulent Ecevit University, School of Medicine, Department of Anesthesiology and Reanimation)

8. MD, Professor Doctor; Bulent Ecevit University, School of Medicine, Department of

Anesthesiology and Reanimation

Submitted on June 13, 2012

Approved on July 30, 2012.

\section{Correspondence to:}

Volkan Hancı MD

Dokuz Eylül Universitesi Araștırma Uygulama Hastanesi Ameliyathaneleri, İnciraltı, İzmir

Phone: +90.530 .643 .32 .40$

E-mail:vhanci@gmail.com infiltration, especially after minor to intermediate surgeries, reduces post-operative opioid consumption and related complications, hospital stay time and costs ${ }^{4}$.

Surgical wound infiltration has been proven to be an effective analgesic and is widely used for post-operative pain relief after abdominal hysterectomy, cesarean section, inguinal hernia repair, lumbar disc hernia, prostatectomy and similar surgeries ${ }^{5-8}$.

When infiltration analgesia is installed before the surgical incision, it preemptively increases analgesic efficiency during and after the operation; additionally, it protects against chronic pain ${ }^{3,5}$.

Local anesthetic agents commonly used for surgical wound infiltration include lidocaine, prilocaine, bupivacaine, ropivacaine and levobupivacaine 1,3-12. Tramadol is a synthetic analogue of codeine, which acts through both opioid and non-opioid mechanisms of action ${ }^{1,13}$. Tramadol has shown similar effects to local anesthetics on peripheral nerves ${ }^{14-20}$. Tramadol may be used as a local anesthetic agent for minor surgeries; similarly, it may be used as an adjuvant to local anesthetics ${ }^{21}$. When added as an adjuvant to local anesthetic agents, it has a similar effect to clonidine and can modify the effects of local anesthetics directly or indirectly by affecting sodium channels and, thus, contributing to more effective analgesia ${ }^{22-27}$.

To be an effective post-operative analgesic, local anesthetics and other medicines used in wound infiltration should ensure quick and uncomplicated healing to prevent post-oper- 
ative morbidity. For this reason, it is important to know not just the effects of the wound infiltration agents on postoperative pain but their effect in detail on wound healing and whether they are a cause of morbidity in clinical use ${ }^{3,28-31}$. Previous research using experimental models and fibroblast tissue cultures from surgical wounds had looked at the effect of local anesthetic agents such as bupivacaine, prilocaine and lidocaine on wound healing 3,28-31. There are no known studies on the effects of tramadol, which may be used for wound infiltration and healing ${ }^{14-21}$.

Our hypothesis was to investigate whether tramadol applied subcutaneously on rats as a surgical wound infiltration anesthetic had any effects on wound healing. To test this hypothesis, the subcutaneous tissue of rats was injected with saline, tramadol, lidocaine and bupivacaine. The effects of these medications on wound healing were investigated by comparing wound stress test results and histopathologic collagen counts.

\section{MATERIAL AND METHODS}

The study was approved by the Animal Ethics Committee of Zonguldak Bülent Ecevit University Medical School. All animals were treated in compliance with the recommendations of the university's animal care committee and the principles of laboratory animal care (NIH publication No. 85-23, revised 1985). The rats were housed in a temperature-controlled room $\left(24 \pm 1{ }^{\circ} \mathrm{C}\right)$ on a 12 -hour-light -12 -hour-dark cycle and were fed with standard rat chow and water for 12 hours prior to the experimental protocol.

Thirty-two male Wistar Albino rats weighing between 250300 grams were randomly separated into four groups of eight animals each. Surgical procedures were done under general anesthesia, induced by intraperitoneal injection of $75 \mathrm{mg} \cdot \mathrm{kg}^{-1}$ ketamine. The hair on the back of the animal was shaved after the loss of cornea reflex and extremity drawing response were diminished. The area of the incision was cleaned with povidione iodine and was wiped dry with sterile gauges after two minutes.

The areas of the incisions were subcutaneously infiltrated with $3 \mathrm{~mL}$ doses of the study drug. The rats in the groups were infiltrated with normal saline in control group (Group C) $(n=8), 2 \%$ lidocaine in lidocaine group (Group $L)(n=8)$, $0.5 \%$ bupivacaine in bupivacaine group (Group $B)(n=8)$, and $5 \%$ tramadol in tramadol group (Group $T)(n=8)$.

After two minutes from study drug infiltration, a 3-cm surgical incision including cutaneous and subcutaneous connective tissue was done with a scalpel under sterile conditions and the tissues were joined with a 4.0 prolene suture. No antibiotics were applied during or after the procedure. The wound was cared for once a day and the animals were euthanized at the end of the 8th day. A band of $6 \times 2 \mathrm{~cm}$ tissue samples were taken from the incision line.

\section{Breaking-Strength Measurements}

For the mechanical tension tests, tissue samples strip shaped $5 \times 5 \mathrm{~mm}$ were taken just from the middle of incision line. In these tests of scar breaking forces, power transducer (FDT 10-A, May IOBS 99; Commat Co., Ankara, Turkey) and data recording system (MP 30 B-CE; Blopac System, Inc., Santa Barbara, CA, USA) were used. Tissues were stretched at the two edges of the tensiometer. Forces leading to rupture of obtained scar are divided into sample size on each sample and standardized as gram. $\mathrm{cm}^{-2} 3,28$.

\section{Histopathological evaluation}

All samples were fixed in $10 \%$ formalin, embedded in paraffin, cut into $5 \mu \mathrm{m}$ sections, and stained with hematoxylin-eosin (H\&E). These sections were then examined under a light microscope for histological changes by a blinded pathologist. Slides were scored for the presence of collagenization, vascularity, edema, and degree of acute and chronic inflammatory cells $(0=$ none, $1=$ mild, $2=$ moderate and $3=$ severe $)$. Mas son's trichrome was also applied for histochemical identification of collagenization. H\&E and Masson's trichrome stained slides were reviewed by the same pathologist 3,28 .

\section{Morphometric analysis}

Morphometric analysis was performed on Masson's trichrome stained histological sections. The number of collagen bundles was measured with Leica, QWINPlus v.3.1.0 software using a Leica (DMLB-100S) microscope. Each slide was measured on one high-power field at $\times 400$ magnification including wound healing area; the mean number of collagen bundles of each group was then calculated ${ }^{3,29}$.

\section{Statistical analysis}

The statistical analysis was performed using Statistical Package for the Social Sciences (SPSS) version 16.0 for Windows (SPSS, Chicago, IL). For the scores and non-normally distributed variables, comparison between groups was done by the Mann-Whitney $U$ and the Kruskal Wallis test. The results were expressed as median (minimum-maximum). A $p$ value $<0.05$ after Bonferroni correction $(p<0.0125)$ was considered significant.

\section{RESULTS}

Three different methods were used to determine wound healing.

\section{Breaking-strength findings}

The first method is the measurement of breaking-strength via tensiometer. When all of the study groups were evaluated according to the breaking-strength measurements, we observed 
a significant difference between the control and Group $L$ $(p=0.001)$, and Group B $(p=0.004)$. There was no significant difference between the control and the Group $T(p=0.029)$. The breaking-strength measurements between Group B and Group L ( $p=0.336)$, Group B and Group T ( $p=0.152)$, Group $L$ and Group T ( $p=0.021)$ were all similar (Table I).

Table I - The Breaking-Strength Measurements.

\begin{tabular}{ll}
\hline Group & Force $($ gram.cm \\
\hline Group C \\
Group L & $201.02(145.12-230.53)$ \\
Group B & $88.35(37.46-165.51){ }^{*}$ \\
Group T & $124.88(48.01-159.26){ }^{*}$ \\
\hline
\end{tabular}

Median (min - max).

*: $p<0.0125$ Compared with Group C, Mann Whitney U.

\section{Morphometric findings}

The second method was a morphometric analysis and collagen bundle counting. When all of the study groups were evaluated according to the number of collagen bundles, we observed a significant difference between the control and Group $L(p<0.001)$, and Group B $(p=0.001)$. There was no significant difference between the control and Group T $(p=0.014)$.
Collagen bundle counts were significantly higher in Group T than in Group L ( $=0.001)$ and Group B ( $=0.004)$. There was no significant difference in the amount of collagen fibers between Group B and Group L ( $p=0.338$ ) (Table II).

Table II - Collagen Bundle Counts.

\begin{tabular}{ll}
\hline Group & Collagen bundle counts \\
\hline Group C & $624(494-710)$ \\
Group L & $265(221-492){ }^{*} \dagger$ \\
Group B & $285(261-510){ }^{*} \dagger$ \\
Group T & $518,50(420-591)$ \\
\hline
\end{tabular}

Median ( $\min -\max )$.

*: $p<0.0125$ Compared with Group C, Mann Whitney U; $\uparrow: p<0.0125$ Compared with Grup T, Mann Whitney U.

\section{Histopathological findings}

The third indicator of wound healing was determined by histopathologic evaluation. When the working groups were compared in relation to edema, vascularity, inflammatory reaction and collagenization, there were significant differences between the control group and Groups $L$ and B. There was no significant difference between the control group and Group T. No significant differences were found between Groups B and $L$, Groups B and T and Groups $L$ and $T$ in terms of the histopathologic indicators of edema, vascularity, inflammatory reaction and collagenization (Table III).

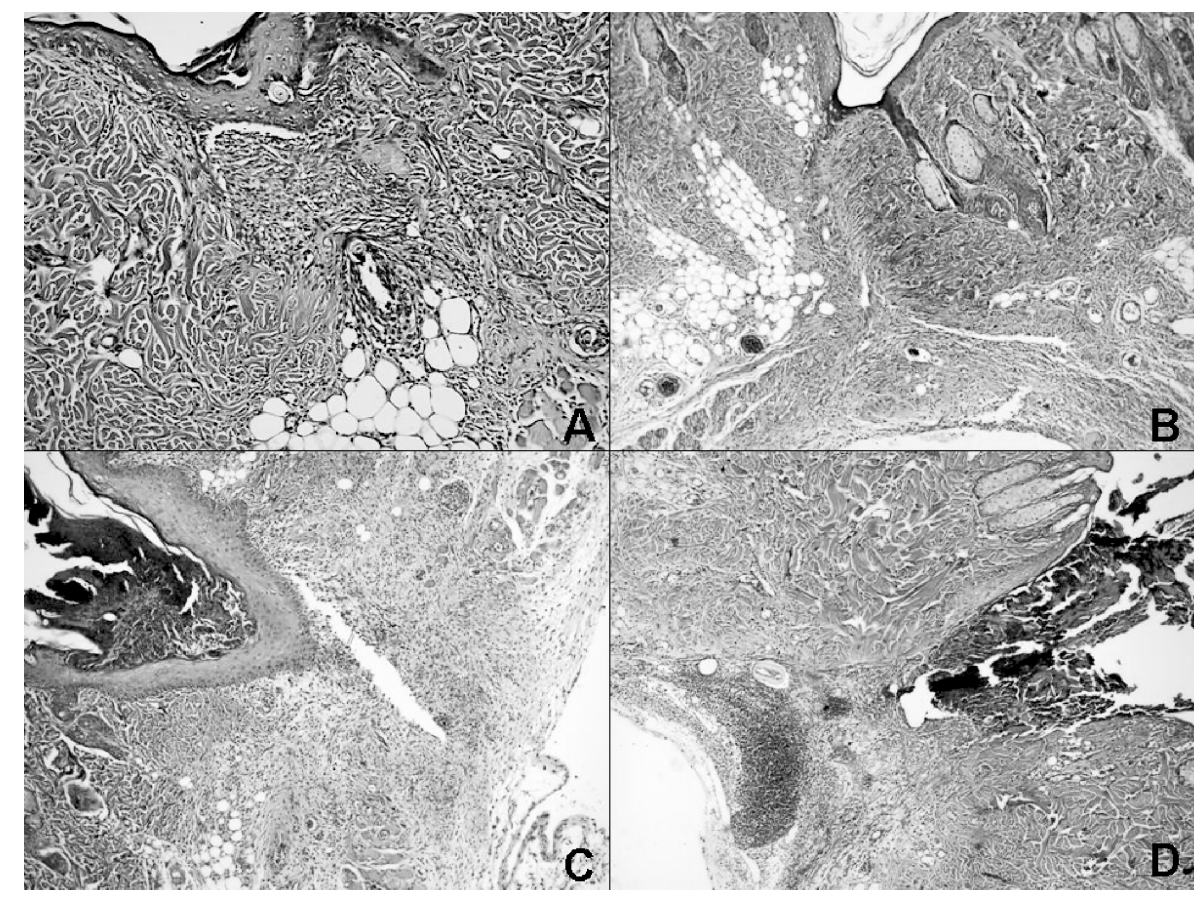

Figure 1 Mild Edema, Inflammation and Vascularity in control (A) and tramadol (B) Groups (H\&E, x400, x100) (B). Moderate edema and severe inflammation in Groups bupivacaine (C) and lidocaine (D) groups (H\&E, x200, x200). 


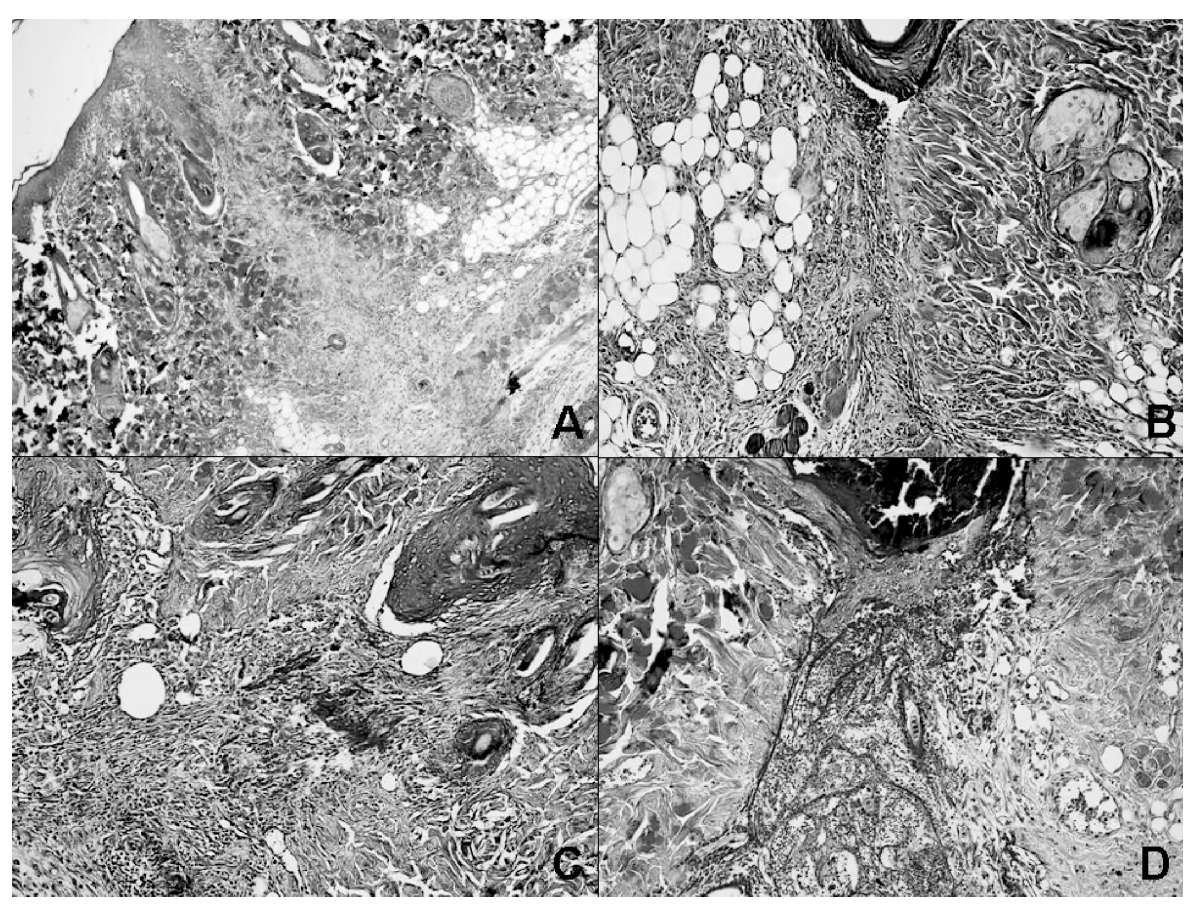

Figure 2 Masson's Trichrome Stain Showing Collagen Fibers (blue) in Wound Healing. Increased collagenization in control (A) and tramadol (B) groups compared to bupivacaine (C) and lidocaine (D) groups (x100, x100, x200, x200).

Table III - Histopathologic Evaluation Scores.

\begin{tabular}{lllll}
\hline Group & Edema & Vascularity & $\begin{array}{l}\text { Inflamma- } \\
\text { tory } \\
\text { reaction }\end{array}$ & $\begin{array}{l}\text { Collage- } \\
\text { nization }\end{array}$ \\
\hline Group C & $1(0-1)$ & $0(0-1)$ & $1(0-2)$ & $3(2-3)$ \\
Group L & $2(2-2)^{\star}$ & $1(1-3)^{\star}$ & $2,5(1-3)^{\star}$ & $1(1-2)^{\star}$ \\
Group B & $2(1-2)^{\star}$ & $2(1-3)^{\star}$ & $3(2-3)^{\star}$ & $1(1-2)^{\star}$ \\
Group T & $1(1-2)$ & $1(0-2)$ & $2(1-2)$ & $2(1-2)$ \\
\hline
\end{tabular}

Median (min - max).

*: $p<0.0125$ Compared with Group C, Mann Whitney U.

\section{DISCUSSION}

Comparing the control group with the groups where bupivacaine and lidocaine were used for wound infiltration, collagen production was lower, breaking-strength measurements showed reduced resistance and significantly high edema, vascularity and inflammation scores were found. Between the control group and the tramadol group, there were no significant differences in collagen production, breaking-strength measurements, as well as edema, vascularity and inflammation scores.

Surgical wound infiltration has been proven to be an effective analgesic and is widely used for postoperative pain relief after abdominal hysterectomy, cesarean section, inguinal hernia repair, lumbar disc hernia, prostatectomy and similar surgeries ${ }^{1,5-8}$. Frequently used local anesthetic agents are lidocaine, bupivacaine, ropivacaine and levobupivacaine 1,3-12 $^{\text {. }}$
Research on the effect of these and other local anesthetic agents used for wound infiltration on wound healing is limited and results are controversial ${ }^{3,28-31}$.

In a histopathologic study that included wound strength tests, rabbits were given $0.5 \%$ lidocaine, $2 \%$ lidocaine and $0.5 \%$ bupivacaine along a midline ventral abdominal wound. Comparing the control group and the test groups, there were no significant differences found in terms of wound tensile scores on any test. The same study emphasized that a comparison of saline and local anesthetic infiltrated tissues found no significant difference in histopathologic results. They concluded that wound infiltration with lidocaine and bupivacaine had no effect on wound healing in midline abdominal incisions in rabbits ${ }^{28}$. Waite et al. ${ }^{29}$ evaluated the effect of lidocaine and bupivacaine on wound healing in mice and found that, although these anesthetics influenced local inflammation and proteolytic factors, they had no effect on wound healing 29.

Other research found that lidocaine and bupivacaine inhibited collagen synthesis in fibroblast tissue cultures, and had cytotoxic effects on different cell lines ${ }^{30-35}$.

A study on guinea pig wound healing when given $1 \%$ lidocaine evaluated breaking strength, number of collagen fibers by morphometry, and histologic examination of collagenization, edema, vascularity, and presence of acute and chronic inflammatory cells. Comparisons with the control group showed that, though there was no significant difference in breaking strength measurements, the lidocaine group had significant vascularity and morphometric differences, as well as a lower amount of collagen ${ }^{30}$. While the application of lidocaine by local infiltration resulted in significant histopathologic changes, the study emphasized that the breaking strength results 
remained the same ${ }^{30}$. Another study on the effects of local anesthetic on human fibroblast found that lidocaine, bupivacaine and ropivacaine produced dose-dependent cytotoxic effects on human fibroblast ${ }^{31}$. Research on lidocaine in wound infiltration of rats found collagenization and effects on mast cell numbers in the wound ${ }^{36}$. Aside from local anesthesia affecting collagen fiber numbers and capillary veins, it may cause varying degrees of inflammation and edema along the wound edges which can affect wound healing 3,37,38.

Past studies have found that the concentration of local anesthetic affects wound healing while high concentrations of local anesthetic delay healing $30,39,40$. While doses inferior to $100 \mathrm{mcg} \cdot \mathrm{mL}^{-1}$ of lidocaine had no effect on healing, in a study of corneal epithelial cells, doses above $250 \mathrm{mcg} \cdot \mathrm{mL}^{-1}$ delayed epithelial healing in a dose-dependent fashion ${ }^{41}$.

Tramadol may be used for peripheral nerve block and in wound infiltration due to its anesthetic effects ${ }^{14-20}$. No study has been found evaluating the effects of tramadol on wound healing, which it is the aim of this study. In our search through the literature, we were not able to find any study that reports the histopathological and physical effects of tramadol on wound healing. We believe our study is the first to concentrate on this subject. Our aim is to evaluate the histopathological and band physical effects of tramadol on the healing of surgical wounds when used for infiltration anesthesia.

While our study found results similar to previous studies on the effects of bupivacaine and lidocaine on wound healing ${ }^{30-}$ 41 , no significant difference was found between tramadol and the control group. The antibacterial properties of local anesthetics and other agents used in wound infiltration are important. Previous research emphasized the antibacterial properties of bupivacaine ${ }^{42-44}$. Controversy surrounds lidocaine antibacterial properties though there are studies in the litera- ture emphasizing its antibacterial properties ${ }^{45}$. However, bacterial strains are not inhibited up to 2 hours after $1 \%$ lidocaine administration and when biopsy cultures are required within two hours, lidocaine should be used ${ }^{46}$. Previous research has evaluated the antibacterial properties of tramadol ${ }^{47}$. Tramadol exhibits dose and time dependent bactericidal activity for $E$. coli and S. epidermidis, and antibacterial against $S$. aureus and $P$. aeruginosa strains. Researchers have emphasized that tramadol may be helpful in reducing bacterial infection risk after local and regional anesthesia due to its antibacterial properties ${ }^{47}$. Our study found no trace of macroscopic infection at the wound site in any subject. This is in accordance with previous studies which emphasized the interaction of local anesthetic and tramadol's antibacterial properties.

Local anesthetics are known for myotoxic effects and when used in infiltration may cause myotoxicity ${ }^{3,48}$. Bupivacaine carries that risk when used as a continuous peripheral nerve block related to the duration of exposure ${ }^{48,49}$. Lidocaine also has myotoxic properties ${ }^{50}$. However, tramadol, without such effects, has been administered intramuscularly for many years ${ }^{51}$.

In conclusion, our study of wound infiltration in rats found bupivacaine and lidocaine reduced collagen production, reduced wound breaking strength, and caused significantly high scores for edema, vascularity and inflammation, when compared to the control group. There was no significant difference between the control group and the tramadol wound infiltration group in terms of collagen production, breaking-strength measurements, and edema, vascularity and inflammation scores. Results of this experimental preliminary study on rats support the idea that tramadol can be used for wound infiltration anesthesia without adverse effect on the surgical healing process. These results need to be verified in humans. 


\section{REFERENCES}

1. Ozyilmaz K, Ayoglu H, Okyay RD et al. - Postoperative Analgesic Effects of Wound Infiltration With Tramadol and Levobupivacaine in Lumbar Disk Surgeries. J Neurosurg Anesthesiol, 2012 Jul 2. [Epub ahead of print].

2. Beaussier $\mathrm{M}$, Bouaziz $\mathrm{H}$, Aubrun $\mathrm{F}$ et al.; les membres du comité douleur - ALR de la Sfar - Wound infiltration with local anesthetics for postoperative analgesia. Results of a national survey about its practice in France. Ann Fr Anesth Reanim, 2012;31:120-125.

3. Dere K, Sen H, Teksoz E et al. - The comparison of the effects of different doses of levobupivacaine infiltration on wound healing. $J$ Invest Surg, 2009;22:112-116.

4. Johansson B Glise H, Hallerback B, Dalman P, Kristoffersson A - Preoperative local infiltration with ropivacaine for postoperative pain relief after cholecystectomy. Anesth Analg, 1994;78:210-214.

5. Vigneau A, Salengro A, Berger J et al. - A double blind randomized trial of wound infiltration with ropivacaine after breast cancer surgery with axillary nodes dissection. BMC Anesthesiol, 2011;11:23.

6. Bari MS, Haque N, Talukder SA et al. - Postoperative pain relief following inguinal hernia repair in children by wound infiltration with levobupivacaine. Mymensingh Med J, 2011;20:586-590.

7. Bilgin TE, Bozlu M, Atici S, Cayan S, Tasdelen B - Wound Infiltration with Bupivacaine and Intramuscular Diclofenac Reduces Postoperative Tramadol Consumption in Patients Undergoing Radical Retropubic Prostatectomy: A Prospective, Double-blind, Placebo-controlled, Randomized Study. Urology, 2011;78:1281-1285.

8. Hernandez Palazon J, Tortosa Serrano JA, Burguillos Lopez S, Molero Molero E - Infiltration of surgical wound with local anesthetic for postoperative analgesia in patients operated for lumbar disc herniation: comparative study of ropivacaine and bupivacaine. Rev Esp Anestesiol Reanim, 2001;48:17-20.

9. Cnar SO, Kum U, Cevizci N, Kayaoglu S, Oba S - Effects of levobupivacaine infiltration on postoperative analgesia and stress response in children following inguinal hernia repair. Eur J Anaesthesiol, 2009;26:430-434.

10. Sorbello M, Paratore A, Morello G et al. - Wound levobupivacaine continuous infusion for postoperative analgesia in living kidney donors: case-control study. Transplant Proc, 2009;41:1128-1131.

11. Kocabas S, Yedicocuklu D, Yuksel E, Uysallar E, Askar F - Infiltration of the sternotomy wound and the mediastinal tube sites with $0.25 \%$ levobupivacaine as adjunctive treatment for postoperative pain after cardiac surgery. Eur J Anaesthesiol, 2008;25:842-849.

12. Memis D, Hekimoglu S, Kaya G, Atakan HI, Kaplan M - Efficacy of levobupivacaine wound infiltration with and without intravenous lornoxicam for post-varicocoele analgesia: a randomized, double-blind study. Clin Drug Investig, 2008;28(6):353-359.

13. Lewis KS, Han NH - Tramadol: a new centrally acting analgesic. Am J Health Syst Pharm, 1997; 54: 643-52.

14. Khajavi MR, Aghili SB, Moharari RS et al. - Subcutaneous tramadol infiltration at the wound site versus intravenous administration after pyelolithotomy. Ann Pharmacother, 2009;43:430-435.

15. Kargi E, Babuccu O, Altunkaya H, Hosnuter M, Ozer Y, Babuccu B, Payasli C - Tramadol as a local anaesthetic in tendon repair surgery of the hand. J Int Med Res, 2008;36:971-978.

16. Kaki AM, Al Marakbi W - Post-herniorrhapy infiltration of tramadol versus bupivacaine for postoperative pain relief: a randomized study. Ann Saudi Med, 2008;28:165-168.
17. Demiraran $Y$, llce Z, Kocaman B, Bozkurt P - Does tramadol wound infiltration offer an advantage over bupivacaine for postoperative analgesia in children following herniotomy? Paediatr Anaesth, 2006;16:1047-1050.

18. Altunkaya $\mathrm{H}$, Ozer $\mathrm{Y}$, Kargi $\mathrm{E}$ et al. - The postoperative analgesic effect of tramadol when used as subcutaneous local anesthetic. Anesth Analg, 2004;99:1461-1464.

19. Altunkaya H, Ozer Y, Kargi E, Babuccu O - Comparison of local anaesthetic effects of tramadol with prilocaine for minor surgical procedures. Br J Anaesth, 2003;90:320-322.

20. Desmeules JA, Piguet V, Collart L, Dayer P - Contribution of monoaminergic modulation to the analgesic effect of tramadol. $\mathrm{Br} \mathrm{J}$ Clin Pharmacol, 1996;41:7-12.

21. Yurtlu S, Hanci V, Kargi E et al. - The analgesic effect of dexketoprofen when added to lidocaine for intravenous regional anaesthesia: a prospective, randomized, placebo-controlled study. J Int Med Res, 2011;39:1923-1931.

22. Memis D, Turan A, Karamanlioglu B, Tükenmez B, Pamukçu Z - The effect of tramadol or clonidine added to intraperitoneal bupivacaine on postoperative pain in total abdominal hysterectomy. J Opioid Manag, 2005;1:77-82.

23. Tsai YC, Chang PJ, Jou IM - Direct tramadol application on sciatic nerve inhibits spinal somatosensory evoked potentials in rats. Anesth Analg, 2001; 92:1547-1551.

24. Acalovschi I, Cristea T, Margarit S, Gavrus R - Tramadol added to lidocaine for intravenous regional anesthesia. Anesth Analg, 2001;92:209-214.

25. Robaux S, Blunt C, Viel E et al. - Tramadol added bupivicaine, morphine and tramadol in rats. Agri, 2004;16:53-58.

26. Jou IM, Chu KS, Chen HH, Chang PJ, Tsai YC - The effect of intrathecal tramadol on spinal somatosensory-evoked potentials and motorevoked responses in rats. Anesth Analg, 2003;96:783-788.

27. Guven M, Mert T, Gunay I - Effects of tramadol on nerve action potentials in rats: comparisons with benzocaine and lidocaine. Int $\mathrm{J}$ Neurosci, 2005;115:339-349.

28. Vasseur PB, Paul HA, Dybdal N, Crumley L - Effects of local anesthetics on healing of abdominal wounds in rabbits. Am J Vet Res, 1984;45:2385-2388.

29. Waite A, Gilliver SC, Masterson GR, Hardman MJ, Ashcroft GS - Clinically relevant doses of lidocaine and bupivacaine do not impair cutaneous wound healing in mice. $\mathrm{Br} \mathrm{J}$ Anaesth, 2010;104:768-773.

30. Drucker M, Cardenas E, Arizti P, Valenzuela A, Gamboa A- Experimental studies on the effect of lidocaine on wound healing. World $J$ Surg, 1998;22:394-397; discussion 397-398.

31. Fedder $\mathrm{C}$, Beck-Schimmer B, Aguirre $\mathrm{J}$ et al. - In vitro exposure of human fibroblasts to local anaesthetics impairs cell growth. Clin Exp Immunol, 2010;162:280-288.

32. Desai SP, Kojima K, Vacanti CA, Kodama S - Lidocaine inhibits NIH3T3 cell multiplication by increasing the expression of cyclin-dependent kinase inhibitor 1A (p21). Anesth Analg, 2008;107:1592-1597.

33. Scherb MB, Han SH, Courneya JP, Guyton GP, Schon LC - Effect of bupivacaine on cultured tenocytes. Orthopedics, 2009;32:26.

34. Harris KL, Bainbridge NJ, Jordan NR, Sharpe JR - The effect of topical analgesics on ex vivo skin growth and human keratinocyte and fibroblast behavior. Wound Repair Regen, 2009;17:340-346.

35. Sturrock JE, Nunn JF - Cytotoxic effects of procaine, lignocaine and bupivacaine. Br J Anaesth, 1979;51:273-281.

36. Rodrigues FV, Hochman B, Wood VT, Simões MJ, Juliano Y, Ferreira LM - Effects of lidocaine with epinephrine or with buffer on wound healing in rat skin. Wound Repair Regen, 2011;19:223-228.

37. Field FK, Kerstein MD - Overview of wound healing in a moist environment (review). Am J Surg, 1994;167:2S-6S.

38. Luostarinen V, Evers H, Lytikainen MT et al. - Antitrombotic effects of lidocaine and related compounds on laser induced microvascular injury. Acta Anesth Scand, 1981;9:25-28.

39. Morris $\mathrm{T}$, Appleby $\mathrm{R}$ - Retardation of wound healing by procaine. $\mathrm{Br} \mathrm{J}$ Surg, 1980;67:391-395.

40. Morris $\mathrm{T}$, Tracey $\mathrm{J}$ - Lignocaine: its effects on wound healing. $\mathrm{Br} \mathrm{J}$ Surg, 1977;64:902-905. 
41. Bisla K, Tanelian DL - Concentration-dependent effects of lidocaine on corneal epithelial wound healing. Invest Ophthalmol Vis Sci, 1992;33:3029-3033.

42. Rosenberg PH, Renkoven OV - Antimicrobial activity of bupivacaine and morphine. Anesthesiology, 1985;62:178-179.

43. Sakuragi $\mathrm{T}$, Ishino $\mathrm{H}$, Dan $\mathrm{K}$ - Bactericidal activity of $0.5 \%$ bupivacaine with presentatives on microorganisms in the human skin flora. Reg Anesth, 1997;22:178-184.

44. Hodson M, Gajraj R, Scott NB - A comparison of the antibacterial activity of levobupivacaine vs. bupivacaine: an in vitro study with bacteria implicated in epidural infection. Anesthesia, 1999;54:683-702.

45. Sedef Gocmen J, Buyukkocak U, Caglayan O, Aksoy A - In vitro antibacterial effects of topical local anesthetics. J Dermatolog Treat, 2008;19:351-353.

46. Berg JO, Mössner BK, Skov MN, Lauridsen J, Gottrup F, Kolmos HJ - Antibacterial properties of EMLA and lidocaine in wound tissue biopsies for culturing. Wound Repair Regen, 2006;14:581-585.

47. Tamanai-Shacoori Z, Shacoori V, Jolivet-Gougeon A et al. - The antibacterial activity of tramadol against bacteria associated with infectious complications after local or regional anesthesia. Anesth Analg, 2007; 105:524-527.

48. Zink W, Seif C, Bohl JR et al. - The acute myotoxic effects of bupivacaine and ropivacaine after continuous peripheral nerve blockades. Anesth Analg, 2003;97:1173-1179.

49. Nouette-Gaulain K, Bringuier S, Canal-Raffin M et al. - Time course of mitochondrial metabolism alterations to repeated injections of bupivacaine in rat muscle. Can J Anaesth, 2010;57836-57842.

50. Foster AH, Carlson BM - Myotoxicity of local anesthetics and regeneration of the damaged muscle fibers. Anesth Analg, 1980;59:727736.

51. Khooshideh $M$, Shahriari A - A comparison of tramadol and pethidine analgesia on the duration of labour: a randomised clinical trial. Aust $\mathrm{N}$ Z J Obstet Gynaecol, 2009;49:59-63. 